\title{
Literatura afro-brasileira: espaços de silêncio e voz
}

\author{
Heloisa Toller Gomes \\ Universidade do Estado do Rio de Janeiro \\ PACC/UFRJ
}

À memória de Clóvis Moura

(1925-2003)

Três figuras de giz me inauguram, recupero no rito a memória que sou.

Edimilson de Almeida Pereira

RESUMO: ESTE TRABALHO DISCUTE ALGUMAS DAS TENDÊNCIAS RECORRENTES DA LITERATURA AFRO-BRASILEIRA CONTEMPORÂNEA - FORMAÇÃO CULTURAL QUE, NUTRINDO-SE DO MULTIFACETADO FILÃO DA CULTURA AFRO-DESCENDENTE A PARTIR DA DIÁSPORA AFRICANA, ABRE-SE NOTADAMENTE PARA O SOCIAL, ENFATIZANDO OS IMPASSES E DILEMAS, REALIZAÇÕES E FRUSTRAÇÕES, GANHOS E RETROCESSOS VIVIDOS, SECULARMENTE, PELA POPULAÇÃO NEGRA NO BRASIL E NO MUNDO.

ABSTRACT: THIS PAPER DISCUSSES SOME OF THE RECURRENT TENDENCIES OF CONTEMPORARY AFRO-BRAZILIAN LITERATURE - A CULTURAL FORMATION WHICH GETS NOURISHMENT FROM THE MULTIPLE SOURCES OF AFRICAN CULTURE SINCE THE AFRICAN DIASPORA AND OPENS ITSELF TO SOCIAL PROBLEMS, EMPHASIZING THE DILEMMAS, FULFILLMENTS AND FRUSTRATIONS, VICTORIES AND DRAWBACKS OF THE BLACK POPULATION IN BRAZIL AND IN THE WORLD, THROUGHOUT THE CENTURIES.

PALAVRAS-CHAVE: LITERATURA AFRO-BRASILEIRA - IDENTIDADE - EXCLUSÃO - ALTERIDADE KEY-WORDS: AFRO-BRAZILIAN LITERATURE - IDENTITY - EXCLUSION - ALTERITY 
vocando o pensamento de Clóvis Moura, encetamos esta breve reflexão sobre a literatura afro-brasileira em seu desenvolvimento histórico e em algumas de suas tendências contemporâneas. O saudoso sociólogo brasileiro, autor de livros memoráveis como Brasil: as raízes do protesto negro e Dialética radical do Brasil negro, referiu-se, neste último trabalho, à "camisa-de-força ritualística da linguagem imposta pelo senhor", que obrigava o escravo "a um código de linguagem passivo e apenas concordante". Embora inibida e reprimida em sua expressão cotidiana, escreveu Clóvis Moura, a comunidade escravizada "expandia-se em manifestações coletivas de libertação simbólica através da palavra e da música” (MOURA, 1994: 203), o que persistiria nos descendentes de escravos que compõem a população negra no Brasil.

Tal perceptiva visão da cultura afro-brasileira em suas origens, enfocada tanto como revide diante da opressão quanto como criação coletiva de libertação simbólica, aponta para as dualidades e paradoxos que invariavelmente presidiriam a trajetória da escrita literária, crítica e jornalística do negro no país. O escravo e o liberto, nos idos da Colônia e da monarquia, servir-se-iam da linguagem do dominador, que passou também a ser a sua, a fim de exercer a positividade do dominado. Para tanto, foi mister dominar essa linguagem e contaminá-la com a experiência vivida, tantas vezes imprimindo nela a carga dos subsídios africanos ancestrais. Operando com freqüência na clandestinidade, foi-lhes necessário explorar as brechas da linguagem - das linguagens, pode-se dizer, pois que não se trata apenas da verbal - para nelas, e através delas, imprimir a sua face, individual e comunal. Daí, em grande parte, a pluralidade de sentidos e a força da ambigüidade que presidem e permeiam a sua expressão.

O discurso cultural afro-brasileiro, tanto no sentido amplo do termo quanto especificamente nas manifestações escritas aqui enfocadas, nunca perdeu de vista a questão da exclusão e da marginalidade - exercendo aquilo que, em outro momento, chamamos a inscrição do excluído ${ }^{1}$. A marca da marginalidade, da linguagem fraturada, da "consciência dupla" (utilizando as palavras do pensador afro-americano W. E. B. Du Bois, 1999) perseverou e persevera na escrita que é vista hoje, na Academia, como um dos recortes mais profícuos e polêmicos dos estudos literários e sociais, o cânone afro-brasileiro.

1 Cf. GOMES e NASCIMENTO, 1998. 
Ao se abordar esse cânone literário enquanto formação discursiva com características próprias, é imprescindível considerar o papel da memória. No movimento reconstrutivo inerente à cultura negra em seu todo, e que perpassa as suas manifestações escritas, elaborou-se o que Muniz Sodré caracteriza como a "reelaboração política do passado a partir da inteligência presente da vida social”. A lembrança implicada, prossegue Muniz Sodré,

não é repetição do igual, e sim o reencontro de pontos críticos do passado por um sistema reinventivo de valores que coincide com o quadro social presente, ele próprio uma recordação estável e dominante, porém aberto à indeterminação da realidade.

(SODRÉ, 1999: 211)

O que é assim transmutado em poesia - aliás, "Cantiga" - nos dias de hoje:

Trançar teus cabelos negra, é

Recordar canções

Ardentes dos dias de sol e das frias

Noites dos tempos.

É traçar as linhas

do mapa de uma nação.

(CELINHA apud ALVES e DURHAM, 1995: 54)

Assim foi-se elaborando, em seu dinamismo próprio, a multifacetada expressão cultural afro-brasileira da qual a face escrita é uma das mais jovens manifestações. As origens dessa expressão perdem-se nas densidades anônimas dos séculos escravistas. Vem a reivindicar ela o estatuto de literatura - embora através de disfarces vários, tais como pseudônimos - apenas a partir de meados do século XIX, ainda imersa na época escravista, com a poesia de Luiz Gama (1830-1882) e a ficção de Maria Firmina dos Reis (1825-1917): ele, assinando-se "Getulino"; ela, "uma maranhense". De início, por necessidade, essa escrita houve por bem submeter-se aos padrões estéticos dominantes. Porém, leituras recentes da produção afro-brasileira oitocentista atestam a 
apenas aparente submissão da ficção pioneira de Maria Firmina dos Reis, em que se destaca o romance Úrsula, de $1859^{2}$.

Por outro lado, são gritantes os desvios da norma na poesia de Luiz Gama: seu poema "Lá vai verso" (incluído em Trovas burlescas, também da década de 1850) faz um uso satírico do decassílabo, desconstruindo a solenidade da métrica ao vinculá-la a inusitados elementos de africanidade:

Oh Musa de Guiné, cor de azeviche,

Estátua de granito denegrido,

Ante quem o Leão se põe rendido,

Despido do furor de atroz braveza;

Empresta-me o cabaço d'urucungo,

Ensina-me a brandir tua marimba,

Inspira-me a ciência da candimba,

Às vias me conduz d'alta grandeza.

E, adiante, uma audaciosa profissão de fé poética:

Quero que o mundo me encarando veja,

Um retumbante Orfeu de carapinha,

Que a Lira desprezando, por mesquinha,

Ao som decanta de Marimba augusta.

(GAMA, 1974: 23-24)

Durante o século XIX - e além - contam-se nos dedos os autores e autoras que direcionaram a sua arte para a problemática racial brasileira, posicionandose a partir da perspectiva do descendente de escravos. Isso não é de admirar. Se, para as populações pobres, alfabetizar-se já constituía então uma proeza, escrever com vistas à publicação era um impasse, em geral intransponível, para negros escravizados e seus descendentes.

A situação persistiu nas primeiras décadas pós-abolição. A par de incomensuráveis obstáculos socioeconômicos vitimando a população recentemente egressa da escravidão, havia a impossibilidade de realçar positivamente

2 V. DUARTE, 2004. 
a África ancestral em tempos tão acirradamente eurocêntricos. Cruz e Sousa (1862-1898), no poema em prosa "Emparedado", tratou contundentemente da questão do intelectual negro em face da incompreensão dos círculos literários, a lhe barrarem o ingresso na comunidade da arte. Publicado postumamente no ano do falecimento do poeta, "Emparedado" é também um pungente grito de amor ao continente de origem:

Artista? Loucura! Loucura! Pode lá isso ser se tu vens dessa longínqua região desolada, lá do fundo exótico dessa África sugestiva, gemente, criação dolorosa e sanguinolenta de Satãs rebelados, dessa flagelada África, grotesca e triste, melancólica, gênese assombrosa de gemidos, tetricamente fulminada pelo banzo mortal.

(CRUZ E SOUSA, 1961: 663)

Ao final do século XIX, os meios cultos afirmavam a "incompatibilidade entre um poeta de origem africana e uma estética simbolista de origem européia" (ESPÍNDOLA, 2007: 10). Tal avaliação, visando naturalmente Cruz e Sousa, sintetizava o primado da ideologia das hierarquias raciais naquelas elites cientificistas, positivistas, naturalistas, evolucionistas.

Dentre os intelectuais mais esclarecidos, Silvio Romero foi capaz de reconhecer a grandeza de Cruz e Sousa, alegando que este "soube dominar os códigos culturais da civilização e da literatura de sua época”. Para Romero, porém - bom filho de seu tempo -, Cruz e Sousa era "o caso único de um negro puro, verdadeiramente superior no desenvolvimento da cultura brasileira". Assim, o poeta catarinense seria, segundo ele, "a prova de que através da incorporação dos elementos de cultura branca européia era possível livrar o país da barbárie" (ESPÍNDOLA, 2007: 11).

A tensão encravada na obra de Cruz e Sousa sugere uma criatividade travada em seu âmago - ou seja, "emparedada", pois que impedida de expandir-se em liberdade além dos parâmetros impostos pelos modelos culturais dominantes nos quais a sua arte foi, afinal, eminente. Sua genialidade não podia contar, ainda, com o suporte de uma estética valorizadora da africanidade, em um quadro ideológico que não era apenas brasileiro. Lembremos que o reconhecimento da cultura negra emergiria na cena internacional apenas a partir da década de 1920, com a Harlem Renaissance nos Estados Unidos, a Negritude afro-franco-caribenha e o inédito interesse do modernismo europeu 
- impulsionado principalmente por Picasso - na arte africana. No modernismo brasileiro, como veremos, a temática do negro seria também, embora intermitentemente, alçada a um nível de interesse inédito até então.

Durante a "belle époque" brasileira, a fase histórica correspondente à Primeira República anterior à revolução modernista, a inserção no fechado e limitadíssimo círculo letrado do país, e a sua superação, significavam façanhas muitas vezes insuperáveis até mesmo para aqueles isentos das barreiras sociais e raciais. Escritores celebrados como Coelho Neto (1864-1934) - "a grande figura literária entre o crepúsculo do Naturalismo e a Semana de 22" (BOSI, 1974: 223) - queixavam-se da estreiteza da cena cultural na própria capital federal. O romancista Aluísio Azevedo (1857-1913), filho de diplomata português no Maranhão e outra das maiores personalidades das letras em sua época, assim se expressou: "Decididamente é melhor ser calceteiro ou condutor de bonde do que homem de letras em um país como este" (SEVCENKO, 2003: 114).

Pura força de expressão. Porque a comunidade pobre, a dos "condutores de bonde" e funções similares, arcava com dificuldades ignoradas pelos filhos da burguesia ilustrada. Apesar das condições adversas, contudo, a inscrição do excluído e, nesta, a dos descendentes de escravos, foi-se gradualmente imprimindo, a partir das franjas e das bordas da linguagem, como já foi dito, e das áridas margens do tecido social - hoje chamadas periferias -, naquelas "abas do Parnaso" a que se referira a lúcida ironia de Luiz Gama, e de onde fora possível ao grande abolicionista perceber a sociedade em que vivia para, dali, exercer a sua crítica e a sua criatividade (GAMA, 1974: 21).

Machado de Assis (1839-1908), "filho de um pintor mulato e de uma lavadeira açoriana” (BOSI, 1974: 193), seria dos pouquíssimos egressos das camadas pobres e mestiças a ingressar e a vencer em tais círculos. À exceção do exercício de cronista, em que se manifestou diretamente sobre os males de sua sociedade, o Machado ficcionista optou pelo linguajar duplo, pela contundência da crítica social cifrada no discurso oblíquo da ironia, numa escrita "marcada pela sutileza dos incessantes deslizamentos de sentido, e que ainda desafia a volumosa recepção crítica dedicada a pesquisar os 'enigmas' legados pelo 'bruxo do Cosme Velho"' (DUARTE, 2007: 239).

Assim também se impôs a expressão romanesca mais direta e desassombrada de Lima Barreto (1881-1922) - com Cruz e Sousa e Machado, os exemplos de superação das circunstâncias e de reconhecimento cultural mais expressi- 
vos que a literatura brasileira conheceu, na virada do século XX e em suas primeiras décadas. Avaliar o que as respectivas vitórias podem ter significado em termos de custos pessoais é material histórico - e tarefa para os biógrafos.

Hoje, a literatura afro-brasileira - que na grande maioria das vezes se apresenta, assumidamente, como letra e fala de uma experiência específica, a do negro no Brasil - tem encontrado inegavelmente mais espaços de expansão. Ela pode ser caracterizada como uma formação discursiva que, por opção, nutre-se do multifacetado filão da cultura afro-descendente a partir da diáspora africana e destaca tal legado, sempre em processo de atualização, contrapondo-o e/ou fundindo-o ao dinamismo das demais heranças socioculturais. Em seu espaço, necessariamente, coabitam camadas de protesto e negociação, adaptação e resistência, silêncio e voz, na problematização de questões de identidade, exclusão e alteridade, e na reivindicação da autoria de um discurso próprio que recusa estereótipos redutores.

A constatação do pendor para a exposição, ou dramatização, de questões sociais não significa sugerir que a problemática social se imponha exclusivamente sobre as diversificadas opções temáticas à disposição do autor contemporâneo, qualquer que seja a sua bagagem existencial. A operacionalização discursiva do veio afro-brasileiro pode ser vista, sim, como um dos diferenciais a caracterizarem a formação discursiva em pauta - não necessariamente na escolha do temário, porém, na estruturação de uma certa escrita. Esta se serve tanto da vertente cultural dita culta, de procedência especificamente portuguesa, ou européia no sentido amplo, quanto da oralidade inerente à expressão cultural africana, do que resulta um trabalho lingüístico específico. A constatação da conjunção entre a fala/escrita erudita e a popular nascida na escravidão não é, aliás, novidade: já em 1933 Gilberto Freyre ressaltava: "A nossa língua nacional resulta da interpenetração das duas tendências", da fusão da expressão da "casa grande" e da "senzala" (FREYRE, 1973: 334).

A literatura afro-brasileira do século XX teve um grande mentor no poeta Solano Trindade (1908-1974) - considerado em geral pela crítica como o primeiro autor negro no Brasil que explorou, deliberada e consistentemente, o manancial do legado africano. Solano "firmou-se como o primeiro grande nome da poesia de temática e vivência negras no Brasil", escreve Nei Lopes, destacando na poesia e no teatro de Trindade "as reivindicações específicas dos negros, no amplo universo da luta de classes” (LOPES, 2004: 658). 
Vejamos como Solano Trindade, no poema "Sou negro", reescreve poeticamente a história do Brasil, enfocando o negro não como vítima, mais ou menos passiva, de circunstâncias maiores, mas como agente transformador da realidade brasileira:

Contaram-me que meus avós

vieram de Loanda

como mercadoria de baixo preço

plantaram cana pro senhor do engenho novo

e fundaram o primeiro Maracatu.

Depois meu avô brigou como um danado

nas terras de Zumbi

Era valente como quê

$\mathrm{Na}$ capoeira ou na faca

escreveu não leu

o pau comeu

Não foi um pai João

humilde e manso"

(TRINDADE, 1997: 123)

Na poesia de Solano Trindade observa-se, ademais, aquilo que tem permanecido constante na literatura afro-brasileira ao longo dos tempos e persevera nos dias de hoje: o falar na primeira pessoa a englobar a consciência comunal, apontando invariavelmente para o coletivo ${ }^{3}$. Em Solano Trindade, e em muitos dos autores e autoras que o sucederam, destacam-se o esmero e a sofisticação poético-lingüística com que a elaboração de um legado múltiplo tem se dado na poesia, na prosa, na dramaturgia, na crítica contemporânea.

Uma das primeiras tentativas de organizar coletivamente a expressão escrita afro-brasileira foi a chamada imprensa negra de São Paulo, que circulou através de jornais de pequena tiragem e duração precária, desde 1915 (ano da

3 A respeito de Úrsula, de Maria Firmina dos Reis, Eduardo de Assis Duarte escreveu: "Sobressai de imediato a postura do sujeito da rememoração, na qual o eu individual deságua num nós coletivo. É o discurso do outro fazendo ouvir pela primeira vez na literatura brasileira a vOz dos escravizados" (DUARTE: 2004, 275). 
fundação do jornal Menelick) até 1963 (quando da publicação de seu último jornal, Correio d'Ébano). Foram todos periódicos produzidos por e voltados para a comunidade negra. Assim o poeta Oswaldo de Camargo se expressa sobre o lamentavelmente pouco conhecido jornalismo negro paulista:

Os jornais que representam o pensamento da coletividade negra variam segundo a múltipla experiência do negro na vida paulistana. Alguns ficaram apenas no nível do contato de notícias sobre um pequeno grupo de negros; outros alcançaram um alto nível de exposição de idéias; outros ainda se propuseram a ilustrar e preparar o negro para o livre debate e procurar soluções dos problemas comuns dentro da comunidade negra.

(CAMARGO, 1979: 30)

Na primeira metade do século XX, a literatura afro-brasileira, exercida majoritariamente por meio do Movimento Negro paulista, emergiu em paralelo ao movimento modernista brasileiro, embora muito pouco tenha interagido com este 4 . Como aqui já se disse, foi durante o modernismo que, no discurso literário brasileiro, a temática do negro despontou com consistência (o negro não mais visto apenas como epicentro de uma crise, a da escravidão, e de uma causa, a da abolição). A consciência da presença do negro como elemento estrutural na formação do país e da nacionalidade, e a (ainda incipiente) atenção voltada para suas manifestações culturais manifestar-se-iam então de forma inédita nas ciências sociais (com Gilberto Freyre e o grupo do modernismo regionalista do Nordeste) e também na literatura brasileira.

No "Manifesto da Poesia Pau-Brasil" (1924), Oswald de Andrade destaca o veio afro-brasileiro, referindo-se à nossa "formação étnica rica. Riqueza vegetal. O minério. A cozinha. O vatapá, o ouro e a dança” (ANDRADE, 1970: 5). Em sua obra ensaística, anos mais tarde (Ponta de lança, 1943-1945), Oswald torna-se mais incisivo. Ele ridiculariza a tese do branqueamento (ainda vigente!) como "suspeita e anacrônica", e refere-se à "mistura milionária que nos trouxe a África, com seus grandes nagôs, seus filões de cultura sudanesa e oriental e seus rijos e álacres trabalhadores do Benin de Angola" (ANDRADE, 1991: 75).

4 Observe-se que o poeta Menotti del Picchia, autor do Manifesto "Arte Moderna" (1922), prefaciou o livro-poema O pequeno bandeirante, de Lino Guedes, de 1937. 
Em 1947, o alagoano Jorge de Lima (1893-1953) reúne em um volume os seus Poemas negros. Dentre eles, o "Poema de encantação", por exemplo, executa um minucioso trabalho lingüístico com vocábulos e sonoridades africanas - "Vos ofereço quitunde, quitumba, quelembe, quingombô" (LIMA, 1997: 97). Compartilhando com diversos de seus contemporâneos da preocupação, constante nas diversas fases do modernismo nacional, com a "redescoberta do Brasil", Jorge de Lima foi um dos que se destacaram (como Mário de Andrade) na exploração da fala popular e, nesta, a de origem africana, incorporando tal legado à sua arte. $\mathrm{Na}$ maior parte destes e de outros exemplos prevalece a visão notadamente "de fora para dentro" da vida e da cultura negras, mas ali já se chama a atenção, de forma inusitada na literatura brasileira até então vigente, para a presença estrutural do componente africano na química cultural e étnica brasileira.

Embora não necessariamente por via direta, a produção cultural afro-brasileira estabeleceu pontes, em sua elaboração, com a arte moderna e a pós-moderna. Lembremos que, desde o modernismo nacional e internacional, a literatura e as artes plásticas, mais estreitamente ligadas, passaram a incorporar em sua concepção e execução técnicas aleatórias, obras em processo, experiências sensoriais e ações práticas dos artistas na natureza ou nas cidades - todo um inventário de conceitos e materiais externos e hostis ao academicismo, numa liberdade criativa aliada à negação do elitismo classista. A escolha de materiais "não nobres" - objetos industriais ou do cotidiano, dejetos e sobras, trastes e restos - como constituintes da criação artística afina-se com a estética livre de amarras, embora nem por isso menos rigorosa em sua execução, da melhor literatura afro-brasileira de hoje.

Tal requintado lavor da linguagem desponta na poesia de autores como o mineiro Edimilson de Almeida Pereira, neste início do novo século. Seu poema "Nos varais", reproduzido a seguir na íntegra, trabalha uma poética que assim se exerce e expõe:

Tudo panos, úmido murcho, como corda antes da música. Tudo uma roupa vasta que a mão separando ajunta. Fios de uns e outros misturados, cada um com seus nomes.

De rito e de longe, de muito 
e nenhum recurso. Tudo um risco para quem torce as costas no tanque. Como as letras na impressora antes dos livros. Tudo roupas para um corpo que se expande todo braços, segurando as peças. A quem atenta são páginas de leituras. (PEREIRA, 2002: 163)

Exige-se daí uma nova cumplicidade com o leitor, e a ausência da militância racial explícita mal encobre e desvela, nos meandros do texto, toda uma riqueza insuspeitada de sentidos - para quem souber ler: "A quem / atenta são páginas de leituras", avisa o poema. Escrita marginal, de alcance atemporal e, no entanto, toda voltada para o presente, atentando para o sagrado e o profano, para o privado e para o social - "De rito e de longe, de muito / e nenhum recurso". A tradição cultural afro-brasileira confirma hoje, em sua expressão contemporânea, a eloqüência de silêncios que se tecem, ardilosamente, entremeados à força da palavra pronunciada.

A par disso, o poema em prosa "Mãos dadas", também de Edimilson de Almeida Pereira, apresenta-se como literatura que se sabe e se quer marginal. Segue-se, também na íntegra, o texto que confere a epígrafe ao presente trabalho:

Mãos dadas

Em mim a curva dos que fabulam desde a margem onde os recados são tempestades. Não têm corpo, não filam garrafas e sua ausência nos morde, quando chamados num copo de água. A hora é de ver quem se apresenta e que objeto pede para a sua dança. Nós, acostumados nos ossos, cosemos a alegria dos mortos. Por dentro e por fora a vida toma outra forma. Três figuras de giz me inauguram, recupero no rito a memória que sou.

(PEREIRA, 2003: 196)

A literatura afro-brasileira tem interagido com outros gêneros culturais e interpretativos, dispondo de todo um repertório imagístico e simbólico de 
procedências várias. Move sua criatividade num universo híbrido - sendo, talvez, a hibridez a sua feição mais duradoura - e sua escrita flui nos movimentos do tempo e do espaço e nas negociações, adaptações, respostas e estímulos às tensões históricas das gerações sucessivas.

O poema "Invasão", de Sônia Fátima da Conceição, pode ser visto como súmula da elaboração dos espaços híbridos em que se tecem o sagrado e o profano, e onde realidades e tradições múltiplas transbordam, contaminandose mutuamente na feitura de uma nova escrita:

\author{
Energizemos as cidades \\ (é o momento) \\ ressoem os atabaques \\ Santo sacrifício \\ sacrifique \\ (um bode) \\ na Santa Eucaristia \\ santo sangue \\ nos cubra \\ a todos \\ AXÉ \\ (CONCEIÇÃO, 1995: 228)
}

Não é a intenção deste trabalho seguir exaustivamente as trilhas da literatura afro-brasileira e listar seus grandes nomes. Em lugar disso, chamo aqui a atenção para a problemática de sua emergência e de seu árduo desenvolvimento, destacando alguns exemplos nessa já abundante e florescente lavra. À guisa de conclusão, gostaria de enfatizar o caráter plural, ambivalente, paradoxal e tantas vezes ambíguo de uma formação discursiva que opera simultaneamente com a demolição e com a construção.

A expressão literária afro-brasileira apropria-se do discurso dominante para questioná-lo e corrompê-lo, com freqüência desvirtuando seus recursos retóricos (a exemplo de Luiz Gama) e a sua capacidade reguladora de conhecimento e mantenedora, ou corretora, da ordem (conforme ensinou Solano Trindade). Inserindo-se em meio a falhas, ou lacunas, do tecido cultural, o discurso marginal de que falamos ocupou historicamente os espaços vazios 
para, a partir destes, construir positividades que desestabilizam os sentidos consagrados, efetuando novas configurações e alterando, assim, a constelação discursiva em que se insere.

A literatura afro-brasileira subtrai do discurso dominante as presumíveis univocidades na medida em que a sua escrita rasura e subverte a construção das narrativas da história oficial, investindo em outras possibilidades de elaboração. É uma escrita que acrescenta, nega, questiona, incomoda - uma vez que, sem perder de vista o futuro, tem "perdas nas mãos", nas palavras da jovem poeta deste século com que encerramos este momento da nossa reflexão (DHY'T'TA, 1995: 122).

\section{Referências Bibliográficas}

ANDRADE, Oswald de. Manifesto da Poesia Pau-Brasil. In: Obras completas - 6. Rio de Janeiro: MEC/Civilização Brasileira, 1970. 1991. Aqui foi o Sul que venceu. In: . Ponta de lança. São Paulo: Globo,

BOSI, Alfredo. História concisa da literatura brasileira. São Paulo: Cultrix, 1974.

CAMArgO, Oswaldo de. A descoberta do frio. São Paulo: Ed. Populares, 1979.

CELINHA [Célia Aparecida Pereira]. Cantiga. In: ALVES, Miriam Aparecida; DURHAM, Carolyn Richarson (Orgs.). Enfim... Nós / Finally... Us: Escritoras negras brasileiras contemporâneas / Contemporary black Brazilian women writers. Colorado Springs: Three Continents Press, 1995.

CONCEIÇÃO, Sônia Fátima da. Invasão. In: ALVES, Miriam Aparecida; DURHAM, Carolyn Richarson (Orgs.). Enfim... Nós / Finally... Us: Escritoras negras brasileiras contemporâneas / Contemporary black Brazilian women writers. Colorado Springs: Three Continents Press, 1995.

CRUZ E SOUSA, João de. Obra Completa. Rio de Janeiro: Aguilar, 1961.

DHYT'TA, Lourdes [Lourdes Benedita da Silva]. Perdas nas mãos. In: ALVES, Miriam Aparecida; DURHAM, Carolyn Richarson (Orgs.). Enfim... Nós / Finally... Us: Escritoras negras brasileiras contemporâneas / Contemporary black Brazilian women writers. Colorado Springs: Three Continents Press, 1995.

DU BOIS, W. E. B. As almas da gente negra. Trad. e org. H. T. Gomes. Rio de Janeiro: Nova Aguilar/Lacerda Editores, 1999.

DUARTE, Eduardo de Assis. Posfácio a Úrsula, de Maria Firmina dos Reis. Florianópolis/ Belo Horizonte, Ed. Mulheres/PUC Minas, 2004. 
. Estratégias de Caramujo. In: DUARTE, Eduardo de Assis (org., ensaio e notas). Machado de Assis afro-descendente. Rio de Janeiro: Pallas, 2007.

ESPÍNDOLA, Elizabete Maria. Cruz e Sousa: modernidade e mobilidade social em Desterro nas últimas décadas do século XIX. Trabalho apresentado no $3^{\circ}$ Encontro Escravidão e Liberdade no Brasil Meridional da UFSC. Florianópolis: maio 2007. via Internet.

FREYRE, Gilberto. Casa-grande e senzala. Formação da família brasileira sob o regime da economia patriarcal. Rio de Janeiro: José Olympio, 1973.

GAMA, Luiz. "Lá vai verso!" e "Prótase”. In: . Trovas burlescas. São Paulo: Ed. Três, 1974.

GOMES, Heloisa Toller; NASCIMENTO, Gizêlda Melo do. Entre bispos e cavalos, no espaço do jogo: a inscrição dos excluídos. Cadernos do Centro de Ciências Sociais da UERJ. Rio de Janeiro: UERJ, 1998.

LIMA, Jorge de. Poema de Encantação. In: - Novos Poemas / Poemas Escolhidos / Poemas Negros. Rio de Janeiro: Nova Aguilar/Lacerda Editores, 1997.

LOPES, Nei. Enciclopédia brasileira da diáspora africana. São Paulo: Selo Negro, 2004.

PEREIRA, Edimilson de Almeida. Nos varais. In: - Zeozório Blues - obra poética 1. Belo Horizonte: Mazza, 2002. . Mãos dadas. In: Casa da Palavra - obra poética 3. Belo Horizonte: Mazza, 2003.

SEVCENKO, Nicolau. Literatura como missão. Tensões sociais e criação cultural na Primeira República. São Paulo: Companhia das Letras, 2003.

SODRÉ, Muniz. Claros e escuros. Identidade, povo e mídia no Brasil. Petrópolis: Vozes, 1999.

TRINDADE, Solano. Sou negro. In: SANTOS, Joel Rufino dos (Org.). Negro Brasileiro Negro. Revista do Patrimônio Histórico e Artístico Nacional. IPHN - Ministério da Cultura, n. 25, 1997. 